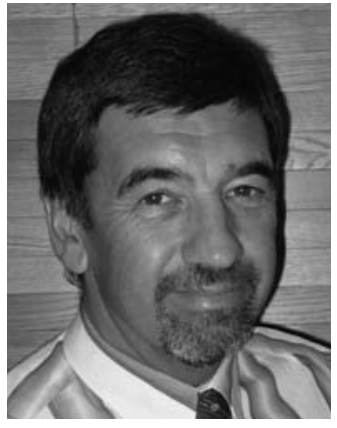

\section{Professor Steve}

\section{Thomas is Director of}

Research at the Business

School, University of

Greenwich in London.

He has been a research

in the field of energy

policy for 35 years,

specialising particularly

in economics and policy

for nuclear power and on liberalisation of electricity markets.
The Economics of Nuclear Energy

While few people now believe that nuclear power would provide 'power too cheap to meter', there is still a common perception that nuclear power is a cheap source of electricity. The fact that nuclear power has not come to dominate electricity generation is seen as being due to a combination of public opposition and dealing with the safety issues raised by accidents such as those at Three Mile Island (1978), Chernobyl (1986) and Fukushima (2011). The reality is that nuclear power has seldom been the cheapest option for new power stations. Worse, the real cost of any normal successful technology goes down over time due to the effect of intuitively sensible factors such as 'learning-by-doing', economies of scale and general technical progress. For nuclear power, these factors do not seem to have worked and for its entire commercial history, the real cost of nuclear power has only ever gone upwards. The Fukushima disaster can only give a further twist to this uprward spiral. This paper examines the determinants of the cost of a kilowatt hour ( $k W h$ ) of nuclear electricity; what the latest designs of nuclear power plant can offer; how new nuclear plants might be financed; and what issues will determine whether South Africa can successfully launch a new nuclear programme.

\section{What Determines the Cost of Nuclear Power? ${ }^{1}$}

Carrying out a detailed cost estimate for the cost of a $\mathrm{kWh}$ of nuclear electricity is a major exercise requiring the estimation of a large number of variables many of which are not easy to forecast. However, it is relatively easy to get an approximate idea of the cost of nuclear power because the costs are expected to be dominated by the 'fixed' costs associated with the construction of the plant. As a rule of thumb, it can be assumed that these fixed costs account for about two thirds of the cost of a $\mathrm{kWh}$ of nuclear electricity. So, to determine whether nuclear power is competitive, we can concentrate on the variables that determine these fixed costs. The variables can be divided into three: the major determinants of the cost of a $\mathrm{kWh}$ (they set the fixed costs); less important determinants; and those that have little impact.

\section{Major Determinants}

- The construction cost: As nuclear power plants are supplied by an international market, this is usually estimated in dollars and to allow fair comparison between different size plants the cost is usually quoted in dollars per kilowatt of installed capacity $(\$ / \mathrm{kW})$. To avoid distortions because the cost of borrowing will vary 
according to the specifics of the plant, the cost is quoted, where possible as if the plant was built 'overnight' with no cost of borrowing.

- The cost of capital: If the company borrows half the money from the market at, say, a real rate of interest (net of inflation) of $8 \%$ and finances the rest from its own resources at, say $12 \%$, the average cost of capital is $10 \%$.

- The plant load factor: Because the cost of nuclear power is dominated by the upfront costs, which have to be paid whether or not the plant is operating, it makes sense to run a nuclear plant at its maximum level for as long as possible so that these fixed costs can be spread out over as many $\mathrm{kWh}$ as possible. The annual load factor is calculated as the number of $\mathrm{kWh}$ it produces, as a percentage of the power it would have produced, if it had operated at full power uninterrupted for the entire year.

A bighly skilled site labour force is required and if this is not available locally, extra costs will be incurred. Other factors include: the cost of building the transmission links needed to connect the station to the national grid; the local geology and seismology; and the method of cooling.

\section{Less Important Determinants}

- Site-specific costs: A relatively small proportion of the cost of a nuclear power plant is covered by the major items of factory produced equipment. The main costs are incurred at the site and include installation, pouring of concrete. There is therefore significant scope for costs of the same design of reactor to vary from site to site. A highly skilled site labour force is required and if this is not available locally, extra costs will be incurred. Other factors include: the cost of building the transmission links needed to connect the station to the national grid; the local geology and seismology; and the method of cooling.

- Non-fuel operating cost: The cost of operating the plant, including maintenance, repair and staffing is relatively low, typically $20 \%$ of the total cost, but not negligible. These costs are not completely fixed - if the plant is permanently closed, they are no longer incurred - but they are relatively fixed while the plant is in service. Some nuclear plants that have required a large amount of maintenance and repairs have been closed because these costs were prohibitive.

- Cost of fuel: Unlike power plants using coal or gas, the cost of fuel is low, typically $5 \%$ including the cost of raw uranium, the cost of turning it into fuel and the cost of disposal after it has been used.

\section{Those with Little Impact}

- Decommissioning cost: The cost of decommissioning a nuclear plant, cleaning up the site and disposing of the radioactive materials (excluding the fuel) - the structure of the plant will become increasingly radioactive over its life - is of the same order of magnitude as the construction cost, but in a normal project appraisal, costs and benefits arising long into the future have much less weight than earlier costs.

- Insurance cost: By international treaty or national law, the liability in the event of an accident of a company owning a nuclear plant is capped at a level far 
below the potential damage cost. The sum varies from country to country, but, typically, a utility would only be liable for damages up to $\$ 200 \mathrm{~m}$, with any other costs borne by the country (taxpayers). The company selling the nuclear plant cannot be held responsible for any damages resulting from an accident.

\section{The Public Perspective}

The costs described above are as perceived by the company which will own and operate the plant. However, from a societal point of view, the perspective is different because taxpayers ultimately must bear the risks. Some costs, such as insurance costs, are potentially huge: costs from Chernobyl and Fukushima are likely to run into hundreds of billions of dollars. Without the guarantee that accident costs would fall on the taxpayer, it is unlikely that many, if any nuclear plants would have been built. Costs far into the future are 'discounted' away in conventional accounting. ${ }^{1}$ In typical project appraisal processes, the value of future liabilities is calculated as the sum of money that would be needed if it was invested today and earned interest till the money was needed-the discounted value. Over a short period of time, this is intuitively sensible. If you have a liability of $\$ 100$ to be paid in a year and you can earn 3\% real interest, a sum of $\$ 97$ invested today would grow sufficiently to pay the required cost. However, over longer periods, this causes some alarming results. If we assume decommissioning costs $\$ 1 \mathrm{bn}$ and is expected to be carried out 100 years after the start-up of the plant and money can be invested to earn 3\% interest, a sum of only $\$ 50 \mathrm{~m}$ is needed. If the period is 150 yearsthe timescale planned for the UK's nuclear power plants- the sum required today is only $\$ 12 \mathrm{~m}$. Similar considerations apply to the disposal of spent fuel.

We have to assume we can forecast accurately
what the cost of a process will be that has
not been done yet (spent fuel disposal)
or not yet done on a commercial scale
(decommissioning) 100 or more years in the
future.

We have to assume we can forecast accurately what the cost of a process will be that has not been done yet (spent fuel disposal) or not yet done on a commercial scale future.

These are not liabilities like repaying a lender. A future generation will have no option but to try to decommission the plants and dispose of the spent fuel. Over such a long period, the assumptions behind the conventional accounting method are hard to justify. We have to assume we can forecast accurately what the cost of a process will be that has not been done yet (spent fuel disposal) or not yet done on a commercial scale (decommissioning) 100 or more years in the future. We then have to assume that we can invest a sum of money in investments with negligible risk of failure at an assured rate of interest over 100 years. The current financial crisis should have alerted everyone that such assumptions are implausible. If the funding method fails or delivers much less money than is needed, a future generation will not only have to carry out these hazardous tasks but it will have to fund them from their own resources.

Fuel is also an important issue. It is unlikely that the price of uranium, which probably represents less than $1 \%$ of the cost of a $\mathrm{kWh}$ of nuclear electricity, will go up to a level at which it would have a significant impact on overall nuclear economics. However, if the price of uranium were to go up, say, 5-fold, this would imply the need to mine poor quality ore. Mining uranium produces large quantities of hazardous (radioactive) waste, which must be carefully dealt with if it is not to contaminate water sources and cause serious health issues. The poorer the quality of ore, the more waste will be produced to get each kilogram of uranium. 


\section{The Latest Designs of Nuclear Plants}

Nuclear power plants are usually categorised according to the coolant used-the fluid that takes the heat from the reactor core to the turbine generator where the electricity is generated-and by the moderator - the material that is used to maximise the chances that when an atom splits, the particle emitted causes another fission. More than $90 \%$ of reactors installed worldwide use water as coolant and moderator, either as a Pressurised Water Reactor (PWR) or a Boiling Water Reactor (BWR). The two reactors at Koeberg are of the PWR type. The Pebble Bed Modular Reactor (PBMR) that South Africa tried to develop from 1998-2010 would have used helium gas as coolant and graphite as moderator.

Nuclear designers attempted to meet this

challenge by producing a new generation

of nuclear power plant designs, still

using water as coolant and moderator,

which offered improved safety and

economics. These became known as

Generation III+ designs...
After the Chernobyl disaster, a combination of poor economics and public concern meant that nuclear power plant ordering reached a low ebb. For example, in Europe and North America, no nuclear orders were placed in the 1990s. Nuclear designers attempted to meet this challenge by producing a new generation of nuclear power plant designs, still using water as coolant and moderator, which offered improved safety and economics. These became known as Generation III+ designs ${ }^{2}$ and optimism in the nuclear industry about their attractiveness was so high that it claimed a 'Nuclear Renaissance' would occur. Under this, countries such as USA, UK, Germany and Italy, which seemed to have turned away from nuclear power, would start ordering large numbers of reactors. ${ }^{3}$

The two designs with the best commercial prospects and which are closest to deployment are the French European Pressurised Water Reactor (EPR) supplied by Areva and the AP1000, a PWR supplied by the Toshiba-owned company, Westinghouse.

The first government to be convinced by their merits was the US which, in 2002, launched its Nuclear 2010 programme, under which it was expected that one or more of these designs would be in service by 2010. It summarised the expected advantages of the Generation III+ designs as follows ${ }^{4}$ :

'New Generation III+ designs have the advantage of combining technology familiar to operators of current plants with vastly improved safety features and significant simplification is expected to result in lower and more predictable construction and operating costs.'

The nuclear industry predicted that these designs could be built for an overnight cost of $\$ 1000 / \mathrm{kW}$ so that a typical reactor with a capacity of $1,000,000 \mathrm{~kW}$ (1000MW) would cost $\$ 1 \mathrm{bn}$. The promises for these designs have proved well wide of the mark and the latest cost estimates are about 5-6 times this level. Only eight reactors using Generation III+ designs have been ordered and six of these are in China and have only started construction in the past couple of years so there is little to be learnt from these.

Construction of the two plants in the West, both EPRs, one in Finland and one in France, has gone badly wrong. Both are now forecast to take at least five years 
longer to build than the 4-5 years expected and their final cost is at least double the forecast level. Far from being simpler, these are now seen as more complex than their predecessors and this has contributed to the problems of controlling construction cost and time. ${ }^{5}$ It seems likely that two orders for AP1000s will go ahead in the USA, the first plants ordered under the US Nuclear 2010 programme. These are unlikely to enter service before 2017-18, more than seven years later than originally envisaged.

\section{Finance}

One of the main hurdles for any nuclear project has been to convince financiers to lend the money to nuclear projects. The record of nuclear plants being built-to time and cost-and operating reliably is poor and recent experience in France and Finland has reinforced this poor reputation. In the past, these economic risks did not matter to financiers in most markets because in a monopoly electricity market, consumers usually pay whatever costs are incurred, so the risk falls on consumers not the financiers.

Even where monopoly remains, consumers are increasingly unwilling to sign a 'blank cheque' to power plant developers and when a nuclear project goes wrong, the company that owns the plant may be forced to take the hit potentially bankrupting it and jeopardising the banks' loans to it. However, electricity markets have increasingly been opened to competition and, in a market, expensive producers go bankrupt and the banks that lent them money lose it. Even where monopoly remains, consumers are increasingly unwilling to sign a 'blank cheque' to power plant developers and when a nuclear project goes wrong, the company that owns the plant may be forced to take the hit potentially bankrupting it and jeopardising the banks' loans to it.

Where nuclear projects are going ahead in the West, invariably there is high confidence that consumers will meet whatever costs are incurred. One alternative to passing the risk to consumers is for the government of the vendor to offer sovereign loan guarantees. This means that if the project goes wrong and the utility building the plant cannot repay the loan, taxpayers would repay the banks. However, this option has disadvantages, especially to the utility's consumers. If the utility is bankrupted, taxpayers from the vendor's home country will step in to repay the bank, but the consumers of the utility will still have to bail out a bankrupt utility.

\section{Prospects for Nuclear Power in South Africa}

Since 1998, the South African government and Eskom have pursued nuclear power with enthusiasm, but no success. From 1998-2010, there was a programme to try to bring the PBMR design to commerciality. This attempt failed, costing around R10bn, mostly of South African public money. ${ }^{6}$ By 2006, Eskom was beginning to look at alternative options to the failing PBMR programme and in January 2008, it launched a tender calling for 3200-3600MW of new capacity from Areva NP and Toshiba/Westinghouse for 3200-3600MW of capacity. ${ }^{7}$ In 2007 , Eskom was expecting bids of about $\$ 2500 / \mathrm{kW} .{ }^{8}$ It was reported that the bids were actually in the order US $\$ 6000 / \mathrm{kW}^{9}$ and in November 2008, Areva was reported to have won the contest. ${ }^{10}$ However, in December 2008, Eskom cancelled the tender citing 'the magnitude of the investment. ${ }^{11}$ Engineering News reported that the issue was the credit rating of Eskom ${ }^{12}$ : 
“... ratings agency Standard \& Poor's said on Thursday that South Africa's National Treasury needed to extend "unconditional, timely guarantees" across all Eskom's debt stock if it hoped to sustain the utility's current BBB+ investment-grade credit rating. The National Treasury was still to announce the details of the package. The Eskom board had, as a result, decided to terminate the commercial procurement process to select the preferred bidder for the construction of the Nuclear-1 project."

Far from being deterred by this experience, Eskom has cast its net wider to include earlier generation designs, on the assumption they would be cheaper. This is expected to bring in reactors from China and Korea. Ironically, the design offered by China, the CPR1000, is effectively an updated version of the design built at Koeberg in the 1980s. This design dates back to the late 1960s. The Korean design is a little newer and is based on a US design from the 1990s. It is expected a formal call for tenders will be launched in 2012 for $9600 \mathrm{MW}$ of capacity. The government is expecting bids of about $\$ 4000 / \mathrm{kW} .{ }^{13} \mathrm{It}$ is hard to understand why the government assumes the cost this time will be only two thirds of the level from four years ago, and how it will be possible to finance $9600 \mathrm{MW}$ when it proved impossible to finance $3600 \mathrm{MW}$ then.

\section{Conclusions}

Nuclear power is an expensive way to generate electricity and even after more than 50 years of commercial development, there is no sign that costs are going to stop increasing. In addition, it is an economically highly risky option because of the poor record of plants being built-to time and cost-and operating as reliably as forecast. The Fukushima disaster serves to underline the problems the nuclear industry was already facing. A new generation of nuclear designs appears close to failure because it is failing to deliver the promises made for it: that they would be safer and because they were simpler, they would be cheaper and easier to build than their predecessors. The Fukushima disaster can only serve to increase their costs and probably their complexity and delay further the time they are commercially available to order.

If it is going to be feasible for new nuclear plants to be financed, it will only be if electricity consumers bear these economic risks, as has always been the case in the past. This economic risk is in addition to the financial risks that the public has always had to bear. These risks arise from the possibility of a catastrophic nuclear accident and the need to dispose of the spent fuel and other radioactive waste and decommission the reactor returning the site to a state where it can be released for unrestricted use.

For South Africa, the latest attempt to place orders for new nuclear plants is not likely to be any more successful than previous attempts. This will waste some public money, but the bigger problem is that for several more years, the government and Eskom will continue to act on the basis that nuclear power can meet its electricity objectives. The options that are capable of meeting these objectives will continue to be neglected.

NOTES

1 For a more detailed review of nuclear economics, see S Thomas (2010) 'The Economics of Nuclear Power: An Update' Heinrich-Böll-Stiftung, Berlin. Also available in Russian and Chinese http://www.boell.de/downloads/ecology/Thomas_economics.pdf

2 There are no clear definitions of the different design generations, but Generation 1 designs include the prototype and demonstration plants of the 1960s, Generation 2 designs include the majority of plants in service now and were ordered in the 1970s and early 1980s. Generation III plants, of which there were relatively few were designed after Three Mile Island and installed from the late 1980s onwards. All Generation III and III+ designs are PWRs or BWRs. A fourth generation of plants has been posited which does not use water as coolant and moderator but these are decades from commercial deployment. It was hoped the PBMR could have been developed into a Generation IV design.

3 For a review of the latest status of the world nuclear market, see M Schneider, A Froggatt \& S Thomas (2011) 'Nuclear Power in a Post-Fukushima World' Worldwatch Institute, Washington, 85pp.

4 US Department of Energy (2003) 'DOE Seeks Public-Private Partnerships To Demonstrate "One-Step Licensing" of New U.S. Nuclear Power Plants' Press Release November 21, 2003. http://nuclear.gov/home/11-21-03.html

5 For a review of the problems incurred at these two sites, see François Roussely, Future of the French Civilian Nuclear Industry (Paris:16 June 2010), translated by the Institute for Energy and Environmental Research, Takoma Park, Maryland, http://www.psr.org/nuclearbailout/resources/roussely-report-france-nuclear-epr.pdf

6 For a review of the PBMR programme, see S D Thomas (2011) 'The Pebble Bed Modular Reactor: An obituary' Energy Policy, vol 39, 5, $2431-2440$.

7 Nucleonics Week 'French consortium to submit bids to build two EPRs in South Africa' Jan 24, 2008, p 5.

8 Nucleonics W eek, "Cabinet Mulls Policy as Eskom Launches Consultation on New Plant", June 7, 2007.

9 Nucleonics Week 'Big cost hikes make vendors wary of releasing reactor cost estimates' Sept 14, 2008.

10 Nucleonics Week 'Eskom to build initial reactors, but long-term plan to be curtailed' Nov 20, 2008.

11 Nucleonics Week 'Eskom cancels tender for initial reactors' Dec 11, 2008, p 1.

12 Engineering News, "Eskom Terminates Nuclear 1 Procurement Process, but SA Still Committed to Nuclear", December 5, 2008

13 Nuclear Intelligence Weekly 'Back to nuclear with aim of 9.6 GW' October 31, 2011, p 6. 